\title{
Proof of concept for turbulence measurements with the RPAS SUMO during the BLLAST campaign
}

\author{
Line Båserud $^{1}$, Joachim Reuder ${ }^{1}$, Marius O. Jonassen ${ }^{1,2}$, Stephan T. Kral ${ }^{3,1,2}$, Mostafa B. Paskyabi ${ }^{1}$, and \\ Marie Lothon ${ }^{4}$ \\ ${ }^{1}$ Geophysical Institute, University of Bergen, Allégaten 70, 5007 Bergen, Norway \\ ${ }^{2}$ UNIS - The University Centre in Svalbard, 9171 Longyearbyen, Norway \\ ${ }^{3}$ Finnish Meteorological Institute, Helsinki, Finland \\ ${ }^{4}$ Laboratoire d'Aérologie, University of Toulouse, CNRS, Toulouse, France \\ Correspondence to: Line Båserud (line.baserud@uib.no)
}

Received: 8 January 2016 - Published in Atmos. Meas. Tech. Discuss.: 1 February 2016

Revised: 15 September 2016 - Accepted: 15 September 2016 - Published: 6 October 2016

\begin{abstract}
The micro-RPAS (remotely piloted aircraft system) SUMO (Small Unmanned Meteorological Observer) equipped with a five-hole-probe (5HP) system for turbulent flow measurements was operated in 49 flight missions during the BLLAST (Boundary-Layer Late Afternoon and Sunset Turbulence) field campaign in 2011. Based on data sets from these flights, we investigate the potential and limitations of airborne velocity variance and TKE (turbulent kinetic energy) estimations by an RPAS with a take-off weight below $1 \mathrm{~kg}$.

The integration of the turbulence probe in the SUMO system was still in an early prototype stage during this campaign, and therefore extensive post-processing of the data was required. In order to be able to calculate the threedimensional wind vector, flow probe measurements were first synchronized with the autopilot's attitude and velocity data. Clearly visible oscillations were detected in the resulting vertical velocity, $w$, even after correcting for the aircraft motion. The oscillations in $w$ were identified as the result of an internal time shift between the inertial measurement unit (IMU) and the GPS sensors, leading to insufficient motion correction, especially for the vertical wind component, causing large values of $\sigma_{w}$. Shifting the IMU $1-1.5 \mathrm{~s}$ forward in time with respect to the GPS yields a minimum for $\sigma_{w}$ and maximum covariance between the IMU pitch angle and the GPS climb angle.

The SUMO data show a good agreement to sonic anemometer data from a $60 \mathrm{~m}$ tower for $\sigma_{u}$, but show slightly higher values for $\sigma_{v}$ and $\sigma_{w}$. Vertical TKE profiles, obtained
\end{abstract}

from consecutive flight legs at different altitudes, show reasonable results, both with respect to the overall TKE level and the temporal variation. A thorough discussion of the methods used and the identified uncertainties and limitations of the system for turbulence measurements is included and should help the developers and users of other systems with similar problems.

\section{Introduction}

The understanding of the complex interaction between the vertical structure of the atmosphere and the characteristics of atmospheric turbulence is of major importance for a wide range of practical applications and for basic atmospheric research. The appropriate parameterization of turbulent exchange processes in numerical weather prediction and climate models or the estimation of structural loads in the field of engineering, e.g., for bridges or wind turbines, are prominent examples.

Vertical profiles of turbulent kinetic energy (TKE) and the underlying velocity variances of the three-dimensional wind vector are excellent indicators for the state of ambient turbulence, as they provide information on both the absolute turbulence level and its spatial characteristics, e.g., local isotropy. They are also of major importance for the understanding of the TKE budget by allowing the estimation of the magnitude of TKE production and vertical transport, which are mech- 
anisms of basic relevance for the determination of turbulent exchange in atmospheric boundary layer (ABL) research.

The measurement of velocity variances requires fastresponse sensors. For in situ observations these are typically mast- or tower-mounted sonic anemometers or multiple-hole flow probes for airborne measurements. Mast- and towerbased measurements can capture the local turbulence conditions in the surface layer and in the case of higher masts and towers, also for the stable ABL as a whole. However, under convective conditions only a fraction of the ABL's vertical extent can be captured, so that important processes, in particular in the entrainment zone, cannot be observed. A few attempts have been started to extend the vertical measurement range by tethered platforms, as balloons, kites or blimps (e.g., Balsley et al., 1999; Muschinski et al., 2001; Majumdar et al., 2006; Guest, 2007; Stevens et al., 2013). Although showing some promising results, these observational platforms require considerable infrastructure and have limitations with respect to wind speed and/or strength of convective turbulence. Remote sensing of velocity variances, e.g., by sodar (e.g., Thomas and Vogt, 1993; Gaynor, 1994; Seibert and Langer, 1996) or lidar systems (e.g., Frehlich, 2008; Pichugina et al., 2008; Sathe and Mann, 2013), is able to reach higher levels in the range of $1 \mathrm{~km}$. Even though these remote sensing methods are of high value for atmospheric research, they cannot fully replace in situ observations as they have typically only limited vertical resolution and sampling rate and as the volume averaging characteristics of these methods require a number of assumptions to derive turbulence parameters for the ABL (e.g., Sjöholm et al., 2009; Sathe et al., 2011).

For these reasons, direct airborne measurements by manned aircraft, providing a unique flexibility with respect to spatial sampling, have become a more popular choice for ABL turbulence investigations during the last decades (e.g., Lenschow and Stankov, 1986; Corsmeier, 2001; Lothon et al., 2007). Corresponding flow probes are either mounted directly on an exposed and undisturbed position on fixed wing aircraft or in an instrument rig towed by a helicopter, as in the case of the Helipod (Bange et al., 2002, 2006). However, these operations are, by nature, logistically demanding and expensive. The rapid development of remotely piloted aircraft systems (RPASs) during the last decade has provided new airborne sensor platforms for ABL research (Elston et al., 2015), with several of them having proven their capability for turbulence investigations (e.g., Thomas et al., 2012; Reineman et al., 2013; Martin et al., 2011; van den Kroonenberg et al., 2012; Braam et al., 2016; Wildmann et al., 2014, 2015). The continuous miniaturization of electronic components and sensors, both for measurement of meteorological parameters and the required attitude control of the aircraft's autopilot, now also provides the required capability for a micro-RPAS, with a take-off weight below $1 \mathrm{~kg}$ (Mansour et al., 2011; Reuder et al., 2012).
The main intention of this paper is the proof of concept for measurements of velocity variance and TKE from the Small Unmanned Meteorological Observer (SUMO), a micro-RPAS with a take-off weight distinctly below $1 \mathrm{~kg}$. The paper is structured as follows. Section 2 briefly describes the RPAS SUMO with a focus on the integrated five-holeprobe-based turbulence measurement system (5HP). The turbulence flights performed during the BLLAST (BoundaryLayer Late Afternoon and Sunset Turbulence) campaign are introduced in Sect. 3, while the required data processing for the calculation of turbulence parameters is described in Sect. 4. This includes the time synchronization of the turbulence and attitude/position data, the transformation into a meteorological coordinate system and the correction of a time shift between the inertial measurement unit (IMU) and the GPS sensors to remove remaining oscillations in the vertical wind component. In Sect. 5, vertical profiles of TKE and their time evolution are presented and discussed for different days during the BLLAST campaign. Section 6 presents an analysis of the different uncertainties, followed by a brief summary and outlook in the final section, Sect. 7.

\section{The SUMO platform}

SUMO is a micro-RPAS with a length and wingspan of $80 \mathrm{~cm}$ and a take-off weight of around $650 \mathrm{~g}$ (Reuder et al., 2009). The SUMO airframe consists of a slightly modified version of the commercially available model aircraft FunJet from Multiplex. The system has been continuously improved and developed during the last years (Reuder et al., 2012).

For navigation and flight control, the system uses the open-source autopilot system Paparazzi, which is developed and maintained under guidance by the École Nationale de l'Aviation Civile (ENAC) in Toulouse, France (ENAC, 2008). SUMO is equipped with an inertial measurement unit (IMU) for attitude control and uses a GPS sensor for navigation and monitoring of the aircraft's position. During the BLLAST campaign, the corresponding data were acquired and stored at $10 \mathrm{~Hz}$ for the IMU and $4 \mathrm{~Hz}$ for the GPS. The SUMO aircraft had no specific constant speed regulation in the configuration during the BLLAST campaign, as this would require the data input from a Pitot tube. This has been avoided on the basis of robustness considerations of the system. The actual speed regulation is done by a control loop based on input information of desired climb speed and GPS velocity. This results (as shown in Fig. 5) in fairly constant values over one flight leg, but in a slight decrease over the whole flight due to the charging level of the battery, which is at the moment only compensated for in a simple linear way. A more detailed description of the SUMO airframe and the sensors used during the BLLAST campaign is given in Reuder et al. (2016).

The most recent development in instrumentation was the integration of a five-hole flow probe (5HP) with a corre- 


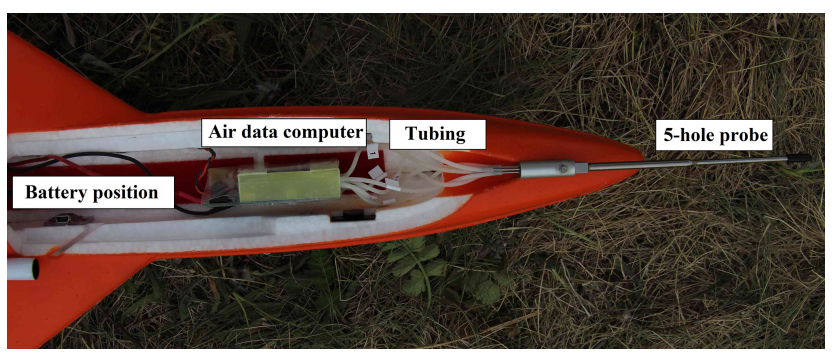

Figure 1. The 5HP and the data computer from Aeroprobe as mounted in the SUMO airframe.

sponding data computer hosting the pressure transducers and data logger (Aeroprobe, 2012). The Aeroprobe data computer provides airspeed, angles of attack and sideslip and altitude based on differential pressure measurements at a temporal resolution of $100 \mathrm{~Hz}$. After correcting for the aircraft's attitude and motion, this enables the calculation of the threedimensional flow vector at a sufficient resolution for calculation of turbulence parameters such as turbulent kinetic energy (TKE).

The 5HP has been calibrated for Mach numbers of 0.044 and 0.088 by the manufacturer, which corresponds to 15 and $30 \mathrm{~m} \mathrm{~s}^{-1}$ respectively. The probe is mounted in the nose of the airframe (see Fig. 1) and is connected to the differential pressure sensors in the data computer by six silicon tubes $10 \mathrm{~cm}$ long. The tip of the sensor is located approximately $10 \mathrm{~cm}$ in front of the fuselage. Wind tunnel tests of the setup, performed at DLR (Deutsches Zentrum für Luft- und Raumfahrt), Göttingen, Germany, in 2014, showed no noticeable effects of flow distortion at this position. The angular response of the probe was tested both stand-alone and mounted on a SUMO airframe, and provided nearly identical results within the accuracy limits of the system. More information on the 5HP system can be found in the manual provided by the manufacturer Aeroprobe (2012) and in Båserud et al. (2014).

During the BLLAST campaign, the 5HP data computer was not integrated into the SUMO's data acquisition system. The 5HP flow data and the aircraft position and attitude were therefore collected on different, unsynchronized data loggers with different temporal resolution. This results in certain challenges with respect to post-processing and will be further described and discussed in Sects. 4 and 6.

\section{SUMO turbulence measurements during BLLAST}

The BLLAST field campaign took place from 14 June to 8 July 2011 in Lannemezan, France. The main goal of the campaign was an in-depth investigation of the turbulence decay during the afternoon transition period. A wide range of $\mathrm{ABL}$ instrumentation was deployed and operated in the area, including energy balance stations, meteorological towers, ra-

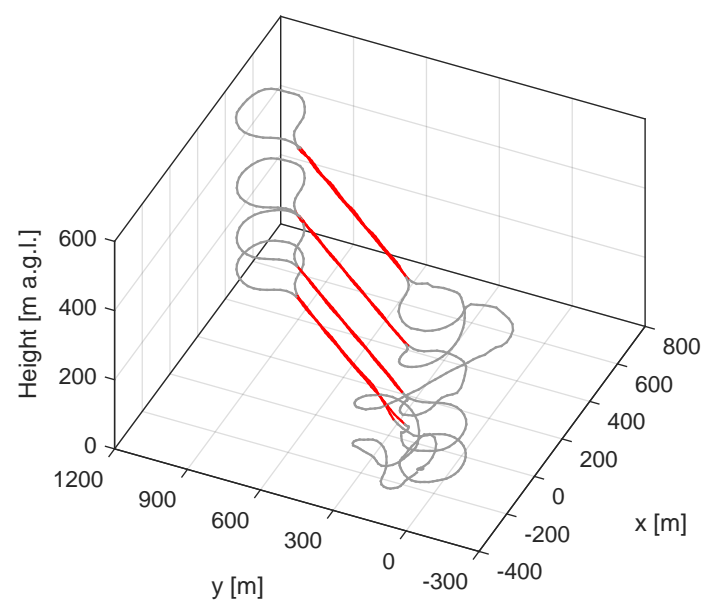

Figure 2. Typical flight pattern for the turbulence measurements from SUMO during the BLLAST campaign. Turbulence parameters are only evaluated for the straight legs (red). This example is from flight no. 38 at 09:15 UTC on 27 June.

diosondes, manned aircraft, RPASs, tethered balloons, and different types of remote-sensing instruments. A comprehensive overview of the scientific goals and the campaign setup is presented in Lothon et al. (2014).

The RPAS SUMO performed a total of 299 flights during the BLLAST campaign, including 49 turbulence transect flights with the 5HP. For more information on the missions the reader is referred to Lothon et al. (2014) and Reuder et al. (2016). All turbulence flights took place in the vicinity of the two main instrumented locations in the campaign area, Site 1 and Site 2 (Lothon et al., 2014). The pattern for all turbulence missions during the BLLAST campaign was similar and consisted of straight legs of around $1000 \mathrm{~m}$ length with circular turns at each end (see Figs. 2 and 3). An overview of all turbulence flights, including the vertical levels probed, is presented in Table 1 . The battery capacity of SUMO allowed for flight missions of 20 to $25 \mathrm{~min}$, corresponding to 8 to 10 straight segments. The most common flight strategies were either four legs at two different altitudes, or two legs at four different altitudes (see Fig. 2).

Two of the 49 flights had to be rejected due to problems with the data loggers. Several other flights had to be excluded from further analysis due to unsatisfactory time synchronization between the 5HP flow data and the IMU/GPS. A description of the corresponding synchronization procedure and the defined acceptance and rejection criteria is given in Sect. 4. Additional flights were excluded due to large deviations from the desired flight level during turbulence segments. Finally a total of 23 flights have been used for the analysis of atmospheric turbulence presented in this study. Four flights (no. 27, 29, 20 and 31), performed close to the $60 \mathrm{~m}$ tower at Site 1 (e.g., Darbieu et al., 2015) at altitudes between 65 and $70 \mathrm{~m}$ (Fig. 3) have been used to compare the SUMO flow measurements with data from a three-dimensional sonic 


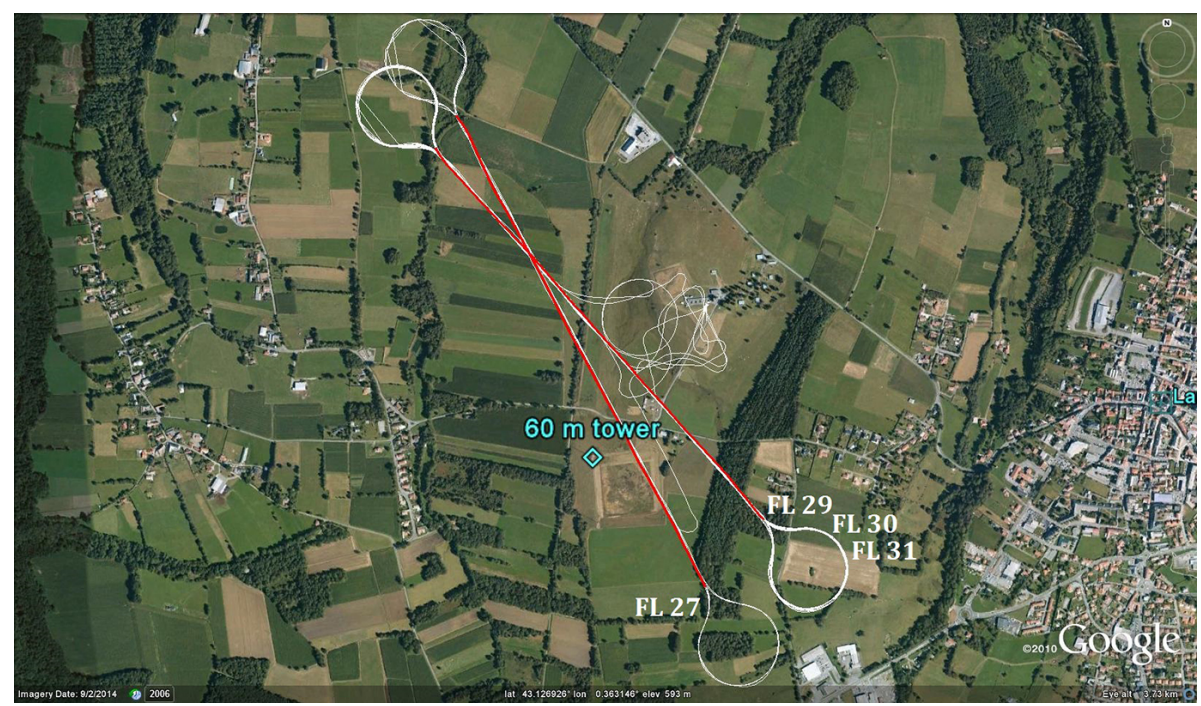

Figure 3. Flight path of the four SUMO flights, no. 27 (65 m a.g.1.), 29 (65 m a.g.1.), 30 (70 m a.g.1.) and 31 (70 $\mathrm{m}$ a.g.1.), in the vicinity of the $60 \mathrm{~m}$ meteorological tower (blue diamond) situated at Site 1 . The straight legs used for calculation of turbulence parameters are marked in red. Each leg is approximately $1 \mathrm{~km}$ long. Satellite picture from Google Earth.
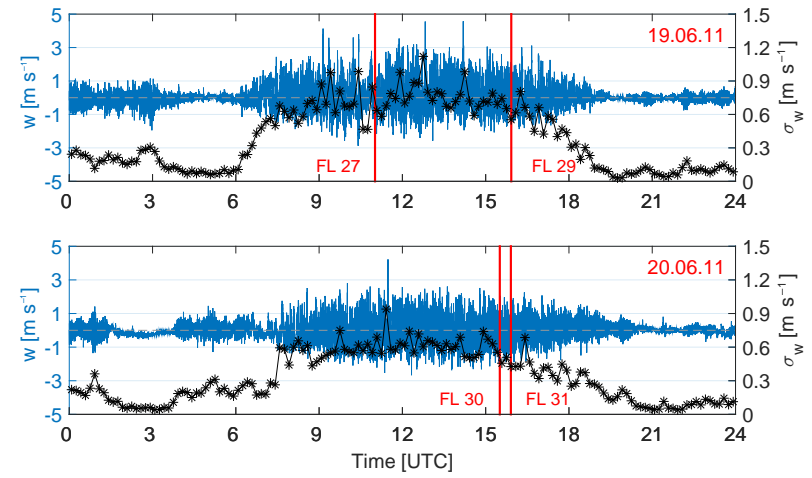

Figure 4. Sonic anemometer measurements $(10 \mathrm{~Hz})$ of vertical velocity, $w$ (blue), and 10 min running mean standard deviation of vertical velocity, $\sigma_{w}$ (black), from the $60 \mathrm{~m}$ meteorological tower for 19 June (top) and 20 June (bottom). The timing of the SUMO flight missions (no. 27, 29, 30 and 31) is indicated by the red lines.

anemometer (Campbell CSAT3) mounted at $60 \mathrm{~m}$ (Fig. 4). Ten flights from 15 June (all with three to four legs at two altitudes) and nine flights from 27 June (all with two legs at four altitudes) at Site 2, have been chosen to investigate the temporal evolution of atmospheric turbulence by the means of TKE profiles (see Sect. 5).

\section{Data processing}

In order to transform the measured flow vector from the SUMO's turbulence system into a meteorological (earthfixed) coordinate system with the velocity components $u$ (positive for wind from the west), $v$ (positive for wind from
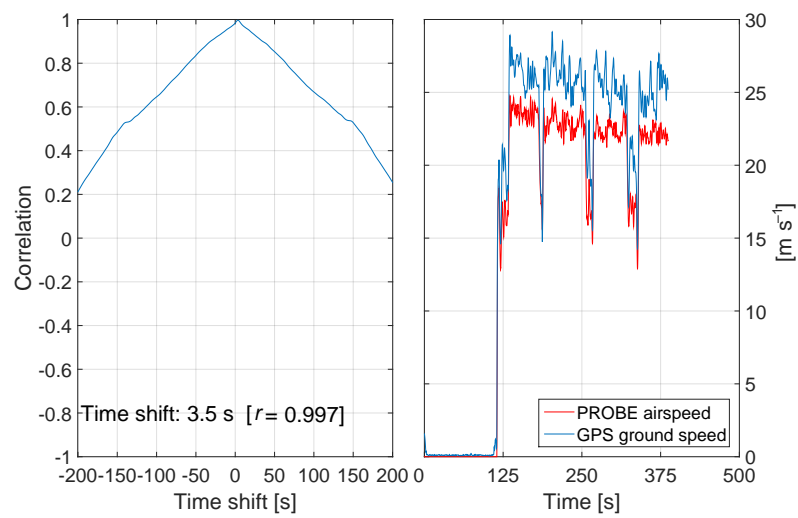

Figure 5. Example of the cross-correlation analysis between the GPS ground speed and the 5HP airspeed for one of the SUMO flights, with correlation coefficient and time shift in the left panel and time series of 5HP airspeed and GPS ground speed after synchronization in the right panel. The data are for flight no. 41 on 27 June at 12:30 UTC.

the south) and $w$ (positive upward), the aircraft's attitude and velocity need to be known with high accuracy. Since the flow and IMU/GPS data relevant for this conversion were recorded on different data loggers, the first step of the postprocessing was to synchronize the flow and IMU/GPS data sets in time. For this the time shift between the airspeed measured by the 5HP and the GPS ground speed was identified by a cross-correlation analysis, calculating the correlation coefficient, $r$, as a function of the time shift. Both velocities are expected to be highly correlated, especially during flight maneuvers, such as start, landing and turns. 
Table 1. All SUMO turbulence transects performed during the BLLAST campaign. The flights used for further analysis are shown in bold. The abbreviation "sshs" refers to the "small-scale heterogeneity site" located at Site 1 . The flight times are all in UTC, and represent the start of each flight.

\begin{tabular}{|c|c|c|c|c|c|}
\hline No. & Date & Time & Site & Alt. (m a.g.1.) & Comments \\
\hline 1 & 13 June & $14: 50$ & 1 & $150,100,65$ & NNE-SSW \\
\hline 2 & 13 June & $15: 14$ & 1 & $65,100,150$ & NNE-SSW \\
\hline 3 & 13 June & $16: 46$ & 1 & $150,100,65$ & NNE-SSW \\
\hline 4 & 13 June & $17: 11$ & 1 & $65,100,150$ & NNE-SSW \\
\hline 5 & 14 June & $12: 15$ & 1 & $150,100,65$ & NNE-SSW \\
\hline 6 & 14 June & $12: 35$ & 1 & $65,100,150$ & NNE-SSW \\
\hline 7 & 15 June & $07: 22$ & 1 & 150,65 & NNE-SSW \\
\hline 8 & 15 June & $07: 37$ & 1 & 65,150 & NNE-SSW \\
\hline 9 & 15 June & 09:50 & 1 & 150,65 & NNE-SSW \\
\hline 10 & 15 June & 10:04 & 1 & 65,150 & NNE-SSW \\
\hline 11 & 15 June & $13: 15$ & 2 & 140,85 & moor \\
\hline 12 & 15 June & 13:32 & 2 & 65,150 & moor \\
\hline 13 & 15 June & 13:56 & 2 & 150,65 & moor \\
\hline 14 & 15 June & $14: 12$ & 2 & 65,150 & moor \\
\hline- & 15 June & $14: 47$ & 2 & 150,65 & $\operatorname{logg}$ fail \\
\hline 15 & 15 June & $15: 03$ & 2 & 65,150 & forest \\
\hline 16 & 15 June & $15: 23$ & 2 & 150,65 & fields $S$ \\
\hline 17 & 15 June & $15: 39$ & 2 & 65,150 & fields $S$ \\
\hline 18 & 15 June & $15: 59$ & 2 & 150,65 & fields $\mathrm{N}$ \\
\hline 19 & 15 June & $16: 17$ & 2 & 65,150 & fields $\mathrm{N}$ \\
\hline 20 & 15 June & $16: 45$ & 2 & 150,65 & fields $\mathbf{N}$ \\
\hline 21 & 15 June & 17:03 & 2 & 65,150 & fields $\mathbf{N}$ \\
\hline 22 & 15 June & $17: 24$ & 2 & 150,65 & fields $\mathrm{N}$ \\
\hline 23 & 15 June & 18:17 & 2 & 150,65 & fields $\mathbf{N}$ \\
\hline 24 & 15 June & $18: 33$ & 2 & 65,150 & fields $\mathbf{N}$ \\
\hline 25 & 17 June & $12: 51$ & 1 & 65 & $\mathrm{~N}-\mathrm{S}$ sshs \\
\hline 26 & 17 June & $13: 32$ & 1 & 65,150 & survey sshs \\
\hline 27 & 19 June & $10: 50$ & 1 & 65 & NW-SE \\
\hline 28 & 19 June & $13: 31$ & 1 & 60 & NW-SE \\
\hline 29 & 19 June & $15: 46$ & 1 & 65 & NW-SE \\
\hline 30 & 20 June & $15: 21$ & 1 & 70 & NW-SE \\
\hline 31 & 20 June & $15: 40$ & 1 & 70 & NW-SE \\
\hline 32 & 25 June & $17: 25$ & 2 & 60 & moor \\
\hline 33 & 25 June & $17: 47$ & 2 & 80 & forest \\
\hline 34 & 26 June & $11: 32$ & 2 & $60,150,300,500$ & moor \\
\hline 35 & 26 June & $11: 49$ & 2 & 80 & forest \\
\hline 36 & 26 June & $14: 31$ & 2 & $60,150,300,500$ & moor \\
\hline 37 & 26 June & $19: 30$ & 2 & $1000,750,500,300$ & moor \\
\hline- & 27 June & 08:09 & 2 & $80,150,300,500$ & $\operatorname{logg}$ fail \\
\hline 38 & 27 June & 09:15 & 2 & $60,150,300,500$ & moor \\
\hline 39 & 27 June & $10: 17$ & 2 & $60,150,300,500$ & moor \\
\hline 40 & 27 June & 11:25 & 2 & $60,150,300,500$ & moor \\
\hline 41 & 27 June & $12: 30$ & 2 & $60,150,300,500$ & moor \\
\hline 42 & 27 June & 13:32 & 2 & $60,150,300,500$ & moor \\
\hline 43 & 27 June & $14: 42$ & 2 & 340 & moor \\
\hline 44 & 27 June & $15: 45$ & 2 & $60,150,300,500$ & moor \\
\hline 45 & 27 June & 17:04 & 2 & 340 & moor \\
\hline 46 & 27 June & 18:12 & 2 & $60,150,300,500$ & moor \\
\hline 47 & 27 June & $19: 41$ & 2 & $60,150,300,500$ & moor \\
\hline
\end{tabular}

The synchronization procedure was applied to all turbulence flights, and the result for one example is presented in Fig. 5. It shows a clear peak of above 0.99 in $r$ for a time shift of $3.5 \mathrm{~s}$. Twenty-two of the flights had an $r$ above 0.97 . Flights with $r_{\max }<0.91$ were removed from further analy- sis. Some additional flights were ignored if a visual inspection revealed several possible time shifts giving high correlation coefficients (broad peak or prominent secondary peaks in the corresponding plots in the left panel of Fig. 5). The time shifts were typically in the range of $\pm 10 \mathrm{~s}$, and are related to different and varying start-up times of the 5HP data computer after switching the power on. A delayed manual start of the ground control station software after connecting the battery of the SUMO aircraft led to time shifts of up to $1 \mathrm{~min}$ on a few occasions.

Furthermore, the IMU and GPS data, which were recorded at a lower rate, were upsampled to the $100 \mathrm{~Hz}$ rate of the $5 \mathrm{HP}$ by linear interpolation. Potential implications of this procedure on the retrieval of turbulence parameters are discussed in Sect. 6.

Thereafter, we identified straight flight legs for our turbulence analysis based on the coordinates used to define the autopilot's flight track, which are recorded during operation. This gave us an objective and automatic way to pick out the straight legs of each flight. The turbulence legs during BLLAST had a typical length of about $1000 \mathrm{~m}$.

The wind speed with respect to the earth is found by performing a coordinate transformation from a Lagrangian into a Eulerian system, based on the velocity of air with reference to the aircraft and the velocity and orientation of the aircraft with respect to the earth. The $u, v$ and $w$ wind components in the earth coordinate system were calculated over straight flight legs based on the well-established equations of Lenschow (1986). The original full set of equations include terms involving the product of angular velocities and the separation distance between the turbulence sensor and the IMU/GPS. According to Lenschow and Spyers-Duran (1989), the contribution of these terms becomes insignificant if the distance is less than $10 \mathrm{~m}$ in the case of a manned aircraft moving at a speed of the order of $100 \mathrm{~m} \mathrm{~s}^{-1}$. For the SUMO system, typically moving with $20 \mathrm{~m} \mathrm{~s}^{-1}$, the separation distance is about $60 \mathrm{~cm}$. We have calculated the size of these additional terms for SUMO, and found them to be of the order of $0.06 \mathrm{~m} \mathrm{~s}^{-1}$ for the vertical component, and even smaller for the horizontal components, and thus too small to make any significant contribution. Consequently we are neglecting these terms. 

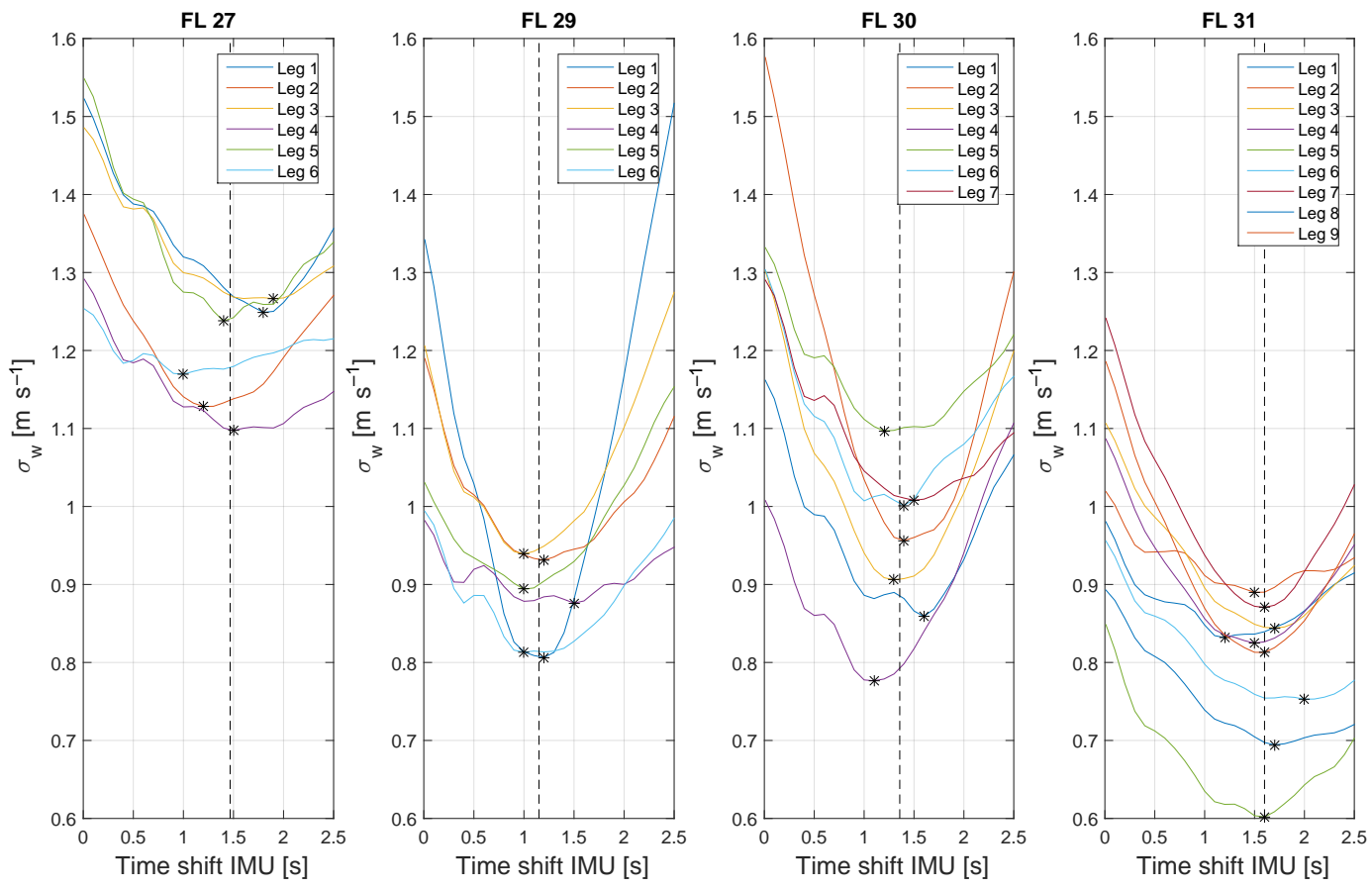

Figure 6. Example of the IMU time shift analysis for flight no. 27, 29, 30 and 31, showing the variation in $\sigma_{w}$ for the range of time shifts between 0 and $2.5 \mathrm{~s}$. The minimum value of $\sigma_{w}$ for each leg can be seen by the black asterisk. The average time shift for each flight is shown by the dashed vertical line.

$$
\begin{aligned}
u= & -\frac{U_{\mathrm{a}}}{\left(1+\tan ^{2} \alpha+\tan ^{2} \beta\right)^{1 / 2}}[\sin \psi \cos \theta \\
& +\tan \beta(\cos \psi \cos \phi+\sin \psi \sin \theta \sin \phi) \\
& +\tan \alpha(\sin \psi \sin \theta \cos \phi-\cos \psi \sin \phi)]+u_{\mathrm{gs}} \\
v= & -\frac{U_{\mathrm{a}}}{\left(1+\tan ^{2} \alpha+\tan ^{2} \beta\right)^{1 / 2}}[\cos \psi \cos \theta \\
& -\tan \beta(\sin \psi \cos \phi-\cos \psi \sin \theta \sin \phi) \\
& +\tan \alpha(\cos \psi \sin \theta \cos \phi+\sin \psi \sin \phi)]+v_{\mathrm{gs}} \\
w= & -\frac{U_{\mathrm{a}}}{\left(1+\tan ^{2} \alpha+\tan ^{2} \beta\right)^{1 / 2}}[\sin \theta \\
& -\tan \beta \cos \theta \sin \phi-\tan \alpha \cos \theta \cos \phi]+w_{\mathrm{gs}}
\end{aligned}
$$

In Eqs. (1)-(3), the 5HP airspeed is given by $U_{\mathrm{a}}$, while the angle of attack and the angle of sideslip are given by $\alpha$ and $\beta$, respectively. The attitude angles' pitch, roll and yaw are given by $\theta, \phi$ and $\psi$ respectively, and the three components of the aircraft's ground speed by $u_{\mathrm{gs}}, v_{\mathrm{gs}}$ and $w_{\mathrm{gs}}$. Due to the lack of a direct measurement for $\psi$, we used the heading angle obtained from the GPS track for this conversion.

After the correction for the aircraft's movement by applying the coordinate transformation (Eqs. 1-3), the resulting $w$ frequently shows features of an oscillation, which seems to be highly correlated with the aircraft's vertical motion. The mentioned oscillations lead to increased values of the stan-

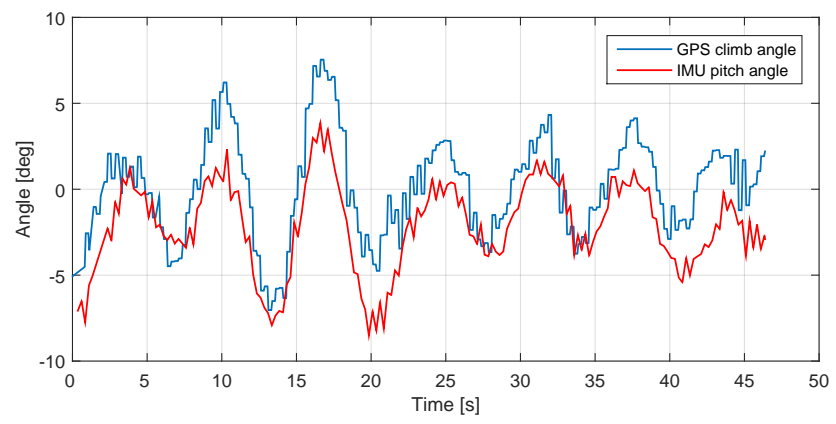

Figure 7. Example of the GPS climb angle and the IMU pitch angle after applying a time shift of $1.2 \mathrm{~s}$ to the IMU, for one single leg (about $1 \mathrm{~km}$ length) of flight no. 29.

dard deviation for the vertical wind component, and thus result in unrealistic estimates of TKE.

Inspection of the magnitude and phase of our contributing terms for Eq. (3) reveals an insufficient cancellation and therefore aircraft motion still remaining in $w$. Based on further investigations of this, we have identified the oscillations in the vertical wind to be the result of an internal time shift between the IMU and the GPS. Internal time lags between sensors (of the order of $1 \mathrm{~s}$ ) were also found by Drüe and Heinemann (2013). The lags arising from slightly different internal data processing procedures (e.g., acceleration-to- 

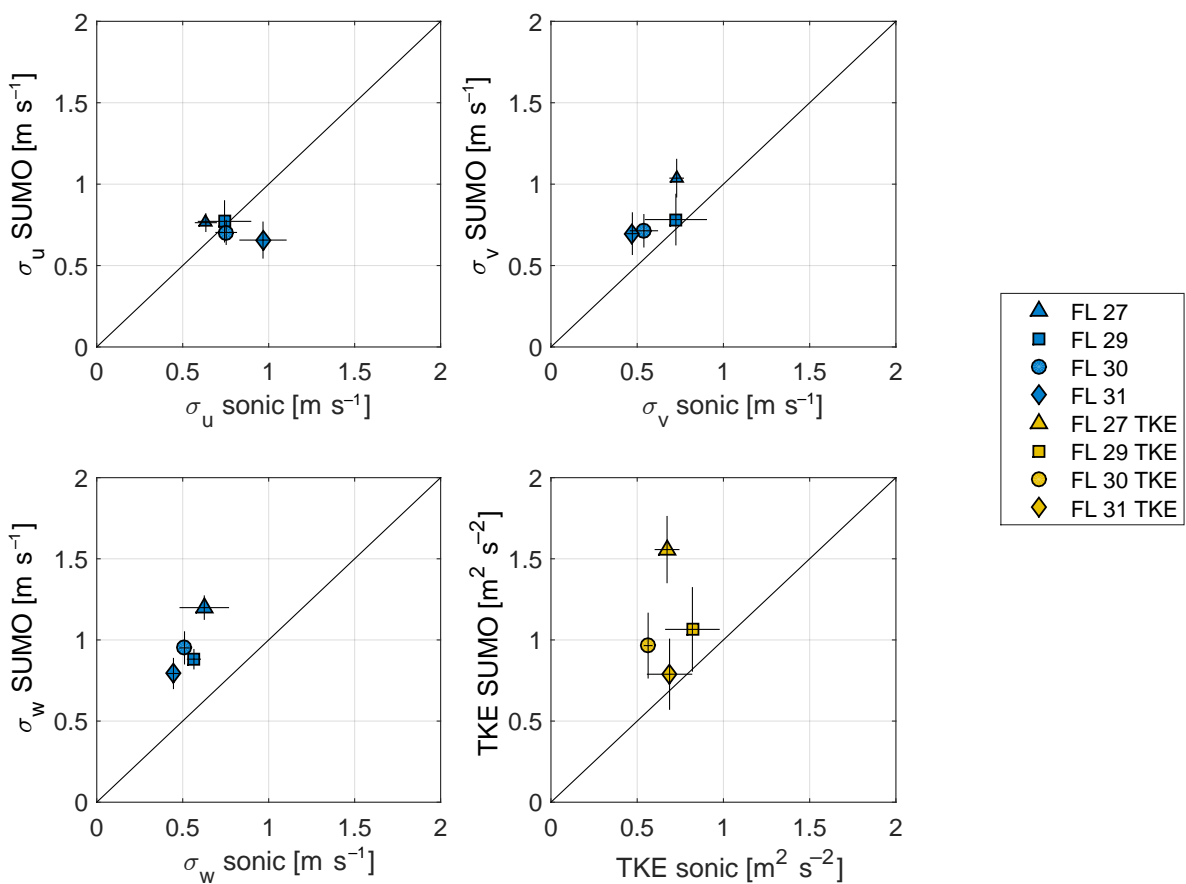

Figure 8. Mean standard deviations of $u$ (upper left panel), $v$ (upper right panel) and $w$ (lower left panel) components of the wind, and mean TKE (lower right panel) from SUMO ( $y$ axis) against the sonic anemometer from the $60 \mathrm{~m}$ meteorological tower ( $x$ axis), for flights no. 27 (triangle), no. 29 (square), no. 30 (circle) and no. 31 (diamond). The black bars show the variation between all the straight legs within each flight for all symbols.

speed/position compared to position-to-speed or by the use of filters) for the individual sensors systems.

A range of time shifts was applied to the IMU for each flight segment, and the value giving the minimum difference between the IMU pitch and the GPS climb angle (a pair of quantities expected to have high covariance) also yielded the minimum in $\sigma_{w}$. Our initial range of time shifts was over several of the periodic oscillations, in both directions, to ensure that the time shift we found was the absolute, and not only a local, minimum. Shifting the IMU pitch forward in time (1-1.5 s) gave a minimum $\sigma_{w}$ for all flight legs from BLLAST. With the IMU pitch and GPS climb angle in phase (see Fig. 7), the oscillations in the first and second part of Eq. (3) cancel out. We have corrected for this time shift by moving the IMU forward in time using the mean time shift obtained over all legs for each flight. Figure 6 presents the time shift analysis for the four flights (no. 27, 29, 30 and 31 ) in the vicinity of the $60 \mathrm{~m}$ tower. One can note the well defined minima in $\sigma_{w}$ for all legs. Some spread between individual legs can be found, especially for legs with less pronounced oscillating features, i.e., the legs that least resemble the pitching calibration maneuver (Lenschow, 1986; Drüe and Heinemann, 2013). However, the difference in minimum $\sigma_{w}$ for the individual legs compared to the flight mean is very small.

A correction was applied to the sonic anemometer measurements to make the data comparable to the SUMO mea- surements. The $u$ and $v$ components were turned into the east/west and north/south directions respectively, by the corrections $u=-u \sin (\beta-\gamma)-v \cos (\beta-\gamma)$ and $v=u \cos (\beta-$ $\gamma)-v \sin (\beta-\gamma)$, where $\beta=63.53^{\circ}$ and $\gamma=112.25^{\circ}$.

\section{Results}

Figure 8 presents the comparison of $\sigma_{u}, \sigma_{v}, \sigma_{w}$, and TKE from SUMO to the data from the sonic anemometer for all four flights in the vicinity of the tower. For SUMO, the $\sigma$ and TKE are first calculated over each straight leg. The resulting average value for one flight (i.e., each symbol in Fig. 8) is the mean over all individual legs within that flight. For the sonic anemometer, the $\sigma$ and TKE are calculated over $10 \mathrm{~min}$ time periods, corresponding to the timing of each individual SUMO leg. The resulting average for one flight (i.e., each symbol in Fig. 8) is the mean over these values.

The data from SUMO fit quite well with the data from the sonic, especially for $\sigma_{u}$. For $\sigma_{v}$, the SUMO data show slightly higher values, and for $\sigma_{w}$ we found SUMO around $0.25 \mathrm{~m} \mathrm{~s}^{-1}$ higher than for the sonic anemometer. Values of TKE are consequently slightly higher for the SUMO. The largest difference between SUMO and the sonic anemometer is found for flight no. 27.

Figure 9 presents the spectra for flight no. 29 from SUMO in comparison to the spectra from the sonic anemometer. The 

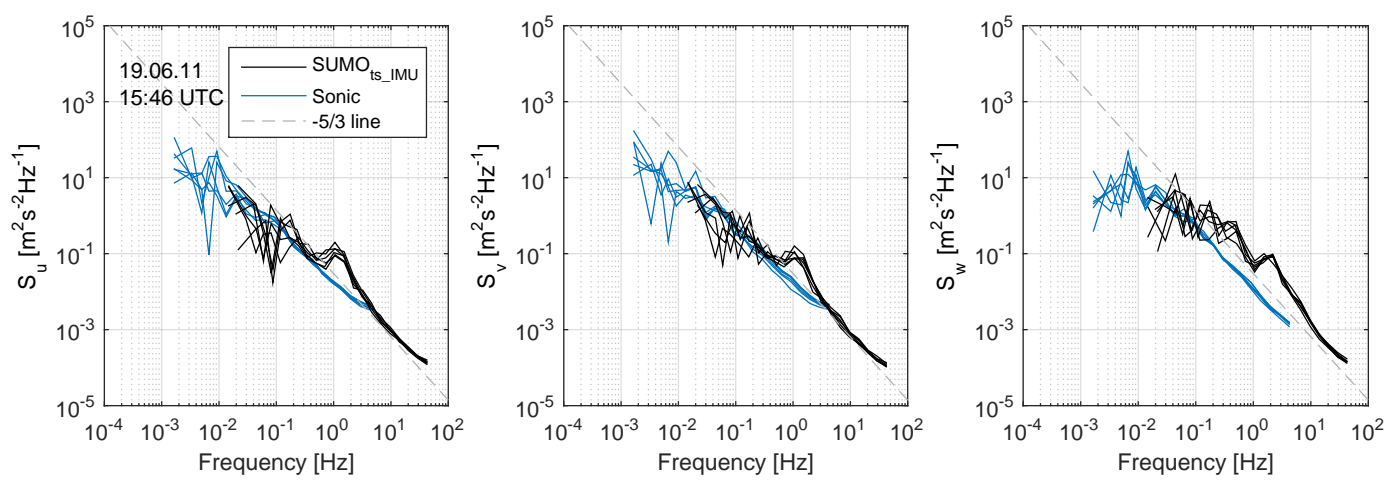

Figure 9. Average spectra for the $u$ (left panel), $v$ (middle panel) and $w$ (right panel) components of the wind from SUMO (black) and the sonic anemometer from the $60 \mathrm{~m}$ tower (blue), for all legs of flight no. 29. The $-5 / 3$ line (dashed gray) indicates the inertial subrange of the spectra.

Table 2. SUMO turbulence transects near the $60 \mathrm{~m}$ tower. Wind direction (WD), wind speed (WS) and the crosswind (CW) component are based on $10 \mathrm{~min}$ average values from the sonic anemometer mounted at $60 \mathrm{~m}$. The maximum error in $\psi\left(\psi_{\text {max }}(\mathrm{err})\right)$ is estimated based on the airspeed from SUMO and the CW. The integral length scales for the sonic at $60 \mathrm{~m}\left(\mathrm{LS}_{\mathrm{S}}\right)$ are calculated using horizontal wind speed over $10 \mathrm{~min}$ averaging periods.

\begin{tabular}{lcrrcccc}
\hline No. & Legs & $\operatorname{Track}\left({ }^{\circ}\right)$ & $\mathrm{WD}\left(^{\circ}\right)$ & $\mathrm{WS}\left(\mathrm{ms}^{-1}\right)$ & $\mathrm{CW}\left(\mathrm{ms}^{-1}\right)$ & $\psi_{\max (\mathrm{err})}\left({ }^{\circ}\right)$ & $\mathrm{LS}_{\mathrm{s}}(\mathrm{m})$ \\
\hline 27 & 6 & $330 / 150$ & 350 & 1.6 & 0.6 & 1.5 & 63 \\
29 & 4 & $320 / 140$ & 317 & 3.6 & 0.2 & 0.5 & 69 \\
30 & 7 & $320 / 140$ & 43 & 2.3 & 2.3 & 5.9 & 21 \\
31 & 9 & $320 / 140$ & 53 & 2.7 & 2.7 & 7.0 & 89 \\
\hline
\end{tabular}

spectra are calculated using a fast Fourier transform analysis of the detrended signals of each individual leg for SUMO and over $10 \mathrm{~min}$ time periods, corresponding to the timing of each leg for the sonic anemometer. Figure 9 presents the average frequency signals for both the SUMO and the sonic.

The SUMO and the sonic spectra for $u$ and $v$ are similar for a wide range of frequencies, both with respect to energy levels and the shape of the spectra. For the $w$ component, the SUMO shows slightly higher energy levels. The spectra follow, however, the $-5 / 3$ slope for the inertial subrange.

Three peaks are visible (at $\sim 1 \mathrm{~Hz}$ for $u$ and $v$ and at $\sim 2 \mathrm{~Hz}$ for $w$ ), which we relate to aircraft control mechanisms in the horizontal and the vertical directions (Reuder et al., 2016). This will be investigated in more detail in the future, so that we can most appropriately remove this contribution from the SUMO data.

The chosen $10 \mathrm{~min}$ averaging period for the sonic data is based on the application of Taylor's hypothesis of "frozen" turbulence (Taylor, 1938), i.e., the time it takes the air mass, probed by SUMO on a straight leg of around $1 \mathrm{~km}$, to be advected past the stationary tower. The wind speeds were generally weak during the whole campaign, with daily average surface winds below $2 \mathrm{~m} \mathrm{~s}^{-1}$ (Lothon et al., 2014). From Table 2 , it is seen that the winds at $60 \mathrm{~m}$ were also weak during the time of the four SUMO flights. A comparison of the flight leg direction with the wind direction shows head- and tailwind for the legs during flights no. 27 and 29 and a weak side wind for flights no. 30 and 31. See Table 2 and Sect. 6 for additional information and discussion of potential uncertainties related to the comparison of the SUMO and the sonic measurements.

Nine flights at Site 2 on 27 June were used to study the time evolution of TKE profiles. Seven of these flights (no. $38,40,41,42,44,46$ and 47) consist of two straight legs at four different altitudes of 60, 150, 300 and $500 \mathrm{~m}$ above ground level (a.g.l.). An example of this type of flight pattern can be seen in Fig. 2. The remaining two flights (no. 43 and 45) consist of eight and nine straight legs at one altitude of $340 \mathrm{~m}$ a.g.l. TKE was first calculated for each straight leg and then averaged over all legs of the same flight at a given altitude. The resulting evolution of the TKE profiles can be seen in Fig. 10.

27 June was a hot and cloud-free convective day, with surface temperatures reaching $30^{\circ} \mathrm{C}$. The boundary layer (BL) height during this day did not behave in a "textbook" manner. It grew fast in the morning and reached a maximum of around $1200 \mathrm{~m}$ (observed with various measurement platforms like ultrahigh-frequency (UHF) wind profilers, radiosondes and RPASs) for a period of less than $1 \mathrm{~h}$ (around 14:00 UTC), before decaying even faster in the afternoon (Lothon et al., 2014). The TKE profiles develop in parallel with this evolution of the boundary layer height. The lowest TKE values 


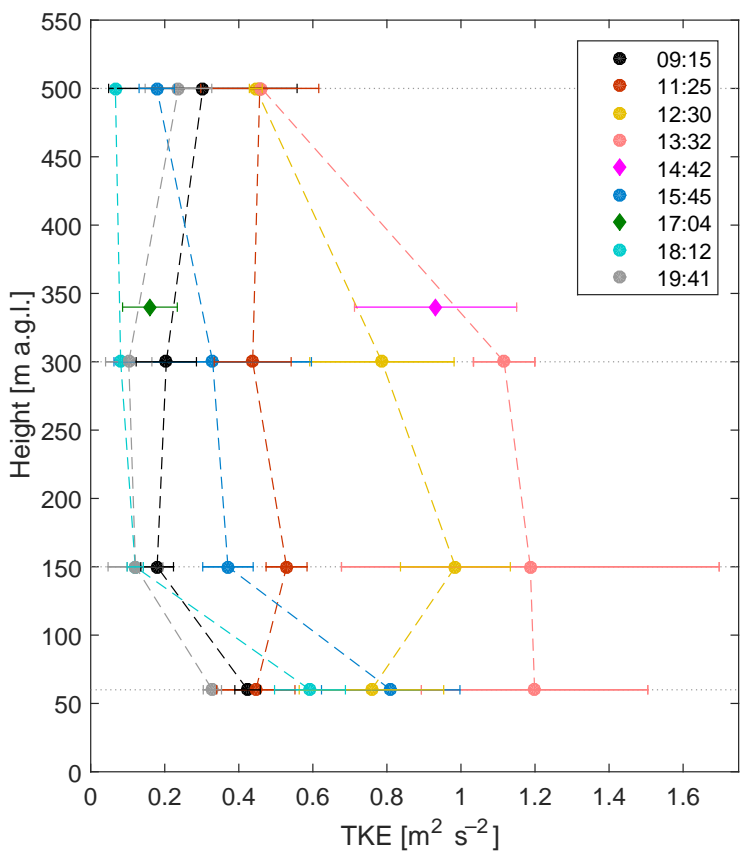

Figure 10. Profiles of TKE from 27 June at Site 2. Consecutive flights are separated by color. The average TKE value over two legs, for each altitude $(60,150,300$ and $500 \mathrm{~m}$ a.g.l.), is shown by the circles. For the two flights with straight legs at $340 \mathrm{~m}$ a.g.l., the diamonds represent the average TKE values. The horizontal bars show the variation between individual legs. The flight times given are all in UTC, and represent the start of each flight.

are observed during morning and evening, with very similar overall levels. The distinct maximum in the early afternoon is limited to a period of less than $2 \mathrm{~h}$. Only this profile exhibits the shape of a typical TKE profile in a fully developed convective boundary layer (CBL), with increasing values with altitude until a maximum is reached at around onethird of the BL height, which is consistent with Stull (1988). The largest diurnal variation is found at 150 and $300 \mathrm{~m}$ a.g.l., while the TKE values vary less in the highest and lowest levels. In particular, the morning and evening profiles show increased values at the lowest level of $60 \mathrm{~m}$, indicating the importance of shear production on TKE during these times. This is supported by the increase in wind speed observed at the surface for the morning and evening (Lothon et al., 2014). The profiles around noon are characterized by TKE values that are rather constant with height. Similar TKE values have been found by Lampert et al. (2016) for flights with the unmanned aircraft $\mathrm{M}^{2} \mathrm{AV}$ from Site 1 on 2 July of the BLLAST campaign, with maximum values between 1.2 and $1.5 \mathrm{~m}^{2} \mathrm{~s}^{-2}$ (200-300 m a.g.1.) at 14:30 UTC, and minimum values below $0.3 \mathrm{~m}^{2} \mathrm{~s}^{-2}(150-300 \mathrm{~m}$ a.g.1.) at 18:30 and 20:30 UTC.

The largest variation between individual legs is found for the flight at 12:30, 13:32 and 14:42 UTC. Especially at 13:32 UTC at $150 \mathrm{~m}$ a.g.l., our straight legs are likely to be

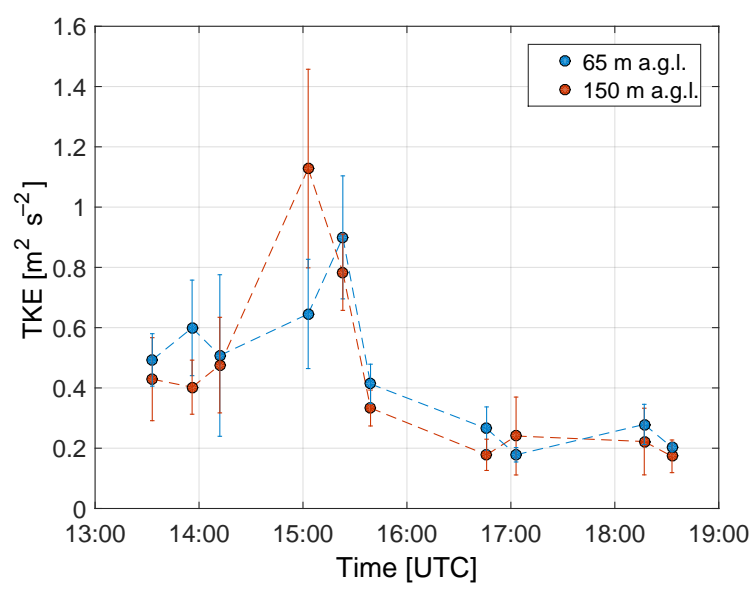

Figure 11. Evolution of TKE from 15 June at Site 2. The colors indicate the different altitudes of 65 (blue) and 150 (red) ma.g.l. Mean TKE over all legs is shown by the circles. The vertical bars show the variation between individual legs. The flight times are all in UTC, and represent the start of each flight.

too short and too few to sufficiently sample the largest eddies (Lenschow and Stankov, 1986).

Figure 11 presents the time series of TKE from 10 SUMO flights during the 15 June at Site 2, which is an example from a day with cloudy weather conditions (Lothon et al., 2014). The BL height grew fast in the morning and reaching values of around $1000 \mathrm{~m}$ around noon and remained nearly constant for a few hours in the afternoon. Each flight during this day consisted of three to four straight legs at both 65 and $150 \mathrm{~m}$ a.g.l. During this day TKE at both levels shows a clear maximum around 15:00 UTC before it rapidly decays throughout the afternoon. This maximum is characterized by higher TKE values at the $150 \mathrm{~m}$ level, again indicating the typical shape of a TKE profile in the developed CBL. During this period we also see the largest spread between the individual legs, again indicating insufficient sampling of the largest eddies (Lenschow and Stankov, 1986). For the rest of the day the TKE values from individual legs within a flight agree more closely, and the values for both levels are also rather similar.

\section{Uncertainty analysis}

The SUMO system was still in a prototype stage during BLLAST when it comes to turbulence measurements, requiring extensive data post-processing and assumptions to be made in order to extract and validate the velocity variance data in three dimensions, which are the basis for the TKE estimation. The following section provides a discussion of the different sources of uncertainty identified and of potential pathways and suggestions to improve the situation in the future. Although some of the issues discussed here have already been improved or solved in the further development of 
the SUMO system, we expect that these methods and techniques can be valuable in a general context, i.e., for the developers and users of other systems with similar problems.

The unsynchronized data loggers of the autopilot and the turbulence probe can cause some uncertainty. One cannot be more accurate in timing than the slowest partner, i.e., GPS (at the moment $4 \mathrm{~Hz}$ ), leaving us with a potential maximum uncertainty of $0.25 \mathrm{~s}$. The upsampling of this GPS data and the $10 \mathrm{~Hz}$ attitude data can change the spectral behavior of the resulting motion-corrected data sets. The latest version of SUMO uses one common data logger for the 5HP and all IMU/GPS data. For newer systems we aim to increase the IMU sampling rate to $100 \mathrm{~Hz}$, and the GPS sampling rate to 10 or $20 \mathrm{~Hz}$, in order to remove these issues completely.

The yaw angle $(\psi)$ has not been measured accurately, but is taken to be the angle of the flight track (heading angle). This simplification might cause an error in the resulting horizontal wind components, and hence, also affect the TKE. However, it can be assumed that this does not lead to large errors as long as the aircraft's ground speed is significantly higher than the side wind component.

We have calculated the crosswind $(\mathrm{CW})$ components for the four flights close to the tower, based on a comparison of the SUMO flight track, and the wind direction (WD) and wind speed (WS) measured by the sonic at $60 \mathrm{~m}$. Estimations of the maximum error in $\psi$, based on the airspeed of SUMO $\left(\sim 22 \mathrm{~m} \mathrm{~s}^{-1}\right)$ and the CW, can be found in Table 2. Following the error estimation in van den Kroonenberg et al. (2008), this will give a maximum error for SUMO below $0.01 \mathrm{~m} \mathrm{~s}^{-1}$ for the $u$ component and below $\pm 0.06 \mathrm{~m} \mathrm{~s}^{-1}$ for the $v$ component, for the four flights close to the $60 \mathrm{~m}$ tower. In addition, during the rest of the campaign, we do not expect considerably higher uncertainties, as the observed wind speeds were relatively low.

Following this argumentation we conclude that the assumptions made for $\psi$ do not lead to significant errors under conditions as experienced during the BLLAST campaign, as winds were weak compared to the aircraft's ground speed of around $20 \mathrm{~m} \mathrm{~s}^{-1}$. For measurements in situations with a strong crosswind component, this has, however, to be taken into account as a potential error source.

When transforming the wind vector from the aircraft to the earth-fixed coordinate system, we have neglected terms involving the product of angular velocities and the separation distance between the turbulence sensor and the IMU/GPS. Tests have shown that the effects of these terms are insignificant for SUMO (of the order of $0.06 \mathrm{~m} \mathrm{~s}^{-1}$ ).

Comparing the measurements of standard deviations and TKE from SUMO to the corresponding measurements from the sonic anemometer mounted at the $60 \mathrm{~m}$ meteorological tower may require some additional considerations regarding the comparability of the two methods. The two basic assumptions that have to be fulfilled are Taylor's hypothesis and horizontal homogeneity. As described by Lothon et al. (2014) the area of interest was characterized by different kinds of surfaces, partially causing significant differences in the surface temperature (Reuder et al., 2016), and consequently in the surface forcing expressed by sensible and latent heat fluxes. These surface heterogeneities are likely to influence the two measurement systems in different ways. The footprint at the stationary tower is only dependent on the meteorological conditions, i.e., stratification, wind speed and direction, which can be assumed to be rather constant with time. In the case of the SUMO platform, the footprint shows an additional dependency on the current location of the airplane, thus being more affected by surface heterogeneity (which makes the measurements so valuable, because they capture a more realistic average of turbulent transport in the area). Additional differences might arise from the horizontal distance between the flight track and the location of the tower and the different averaging procedures that have to be applied to calculate mean turbulent quantities, i.e temporal and spatial averaging.

The averaging period of $10 \mathrm{~min}$ for the tower data does not exactly correspond to the averaging distance of $1 \mathrm{~km}$ of the horizontal flight legs of all flights. This choice is based on a compromise between having a long enough period for good statistics and a short enough period to ensure stationary conditions. Table 2 presents the integral length scales calculated from horizontal wind speed for the $10 \mathrm{~min}$ averaging periods from the sonic $(60 \mathrm{~m}$ tower). The values are between 60 and $70 \mathrm{~m}$ for flights no. 27 and 29 , slightly above $20 \mathrm{~m}$ for flight no. 30 and almost $90 \mathrm{~m}$ for flight no. 31 .

The SUMO legs (around $1 \mathrm{~km}$ length) might be too short (and too few) to capture the largest turbulent scales. This is evident from the spread between individual legs, especially during the highly turbulent regimes (Figs. 8, 10 and 11). Figure 9 also indicates that SUMO has trouble capturing the turbulent production scales.

\section{Summary and outlook}

We present turbulence measurements from the BLLAST field campaign, conducted in summer 2011, obtained using the Aeroprobe 5HP system on board the micro-RPAS SUMO. This system was still in an early prototype stage during the BLLAST campaign, and extensive post-processing of the resulting data was therefore needed in order to calculate the turbulence parameters. The 5HP and the autopilot data loggers were not yet synchronized, for example. We solved this problem through cross-correlating the airspeed measured by the 5HP and the ground speed from the GPS, and correcting for the corresponding time shift. Furthermore, an oscillation in the vertical wind component was discovered. We identified this as the result of an internal time lag between the IMU and the GPS sensor systems. Shifting the IMU 1-1.5 s forward in time with respect the GPS yields a minimum for $\sigma_{w}$ and a maximum covariance between the IMU pitch angle and the GPS climb angle. 
The resulting standard deviations of the three wind components, $\sigma_{u}, \sigma_{v}$ and $\sigma_{w}$, together with TKE from four SUMO flights, compare fairly well with measurements from a sonic anemometer mounted at $60 \mathrm{~m}$ on a meteorological tower, with the SUMO showing slightly higher values. Vertical profiles of TKE, obtained from consecutive flight legs at different altitudes, show low TKE values during morning and evening, and higher TKE values during early afternoon, which would be expected given the time development in surface forcing and corresponding ABL structure on the investigated days.

Since the BLLAST campaign, the SUMO system has been improved in several regards. The aircraft attitude and 5HP data are now synchronized on board, and are logged using one single data logger. There are no longer problems with suboptimal aircraft attitude (pitch) control tuning, which we believe was the cause for the observed low-frequency oscillating aircraft motion observed for the BLLAST campaign. Battery technology is in rapid development, and new batteries have become available since BLLAST, allowing for flights lasting up to $1 \mathrm{~h}$. For turbulence measurements this enables us to perform flights with either longer straight segments or an increased number of straight segments per flight, both increasing the statistical relevance of our measurements. This also gives us the additional flight time needed to perform in-flight calibration routines (Lenschow, 1986; Drüe and Heinemann, 2013) before measurement flights. It is evident that this is crucial to detect e.g., mounting errors and flow distortion effects for the sensors. This can also help to identify time lags between individual sensor systems, as a correlation analysis will be aided by having the quantities cover a sufficient wide range of values. In addition, a fast-response temperature sensor (Wildmann et al., 2013) has been tested with the system, allowing for the direct estimation of turbulent fluxes of sensible heat.

Still, some challenges with the system remain. Currently, the GPS heading data are used for estimating the aircraft yaw angle. For cases with weak crosswinds, such as those presented herein, this has minor influences on the estimated turbulence parameters since the deviation from the true yaw angle is minimal. However, for cases with strong cross-winds we have previously observed larger deviations. To address this shortcoming in the future, we are looking into possibilities of measuring the true yaw angle directly, e.g., by magnetometers or the use of two differential GPS receivers. In addition, the present SUMO airframe and the mounting of the 5HP exposed and unprotected in the nose of the aircraft require an expert pilot for safe landings. In the future, alternative airframes or an alternative mounting of the 5HP will be considered for increased user-friendliness.

As described in the introduction, the potential of the turbulence measurement capabilities of the presented SUMO system cover a wide range of applications and extends beyond basic research on atmospheric turbulent characteristics. Other example applications include the validation of numeri- cal weather prediction models, the characterization of wakes within wind farms and the estimation of turbulent heat fluxes when the system are combined with a fast-response temperature sensor.

\section{Data availability}

The data used in this study are freely available from the BLLAST database: http://bllast.sedoo.fr/database (BLLAST, 2016).

Acknowledgements. The BLLAST field experiment was made possible thanks to the contribution of several institutions and support: INSU-CNRS (Institut National des Sciences de l'Univers, Centre national de la Recherche Scientifique, LEFE-IDAO program), Météo-France, Observatoire Midi-Pyrénées (University of Toulouse), EUFAR (EUropean Facility for Airborne Research) and COST ES0802 (European Cooperation in Science and Technology). The field experiment would not have occurred without the contribution of all participating European and American research groups, which all have contributed a significant amount.

The BLLAST field experiment was hosted by the instrumented site of Centre de Recherches Atmosphériques, Lannemezan, France (Observatoire Midi-Pyrénées, Laboratoire d'Aérologie). BLLAST data are managed by SEDOO, from Observatoire Midi-Pyrénées.

The participation of the Meteorology Group of the Geophysical Institute, University of Bergen, was facilitated by contributions of the Geophysical Institute and the Faculty of Mathematics and Natural Sciences under the "smådriftsmidler" scheme, a travel stipend by the Meltzer Foundation in Bergen, and the Short Term Scientific Mission (STSM) scheme within the COST Action ES0802 "Unmanned Aerial Vehicles in Atmospheric Research".

The authors are grateful to Anak Bhandari for the technical assistance in the preparation of the campaign, and to Christian Lindenberg, the SUMO chief pilot during the campaign. Without his passion, determination and patience we would never have achieved this large number of flights.

We are also grateful to Detlef Hübner from DLR (Deutsches Zentrum für Luft- und Raumfahrt) in Göttingen, Germany, for facilities and technical assistance during the wind tunnel experiments with SUMO in 2014.

Edited by: E. Pardyjak

Reviewed by: two anonymous referees

\section{References}

Aeroprobe: On-The-Fly! Air Data System User's Manual Revision F, 1/2012, available at: https://recuv-ops.colorado.edu/.../OTF_ Manual.pdf, 2012.

Balsley, B. B., Jensen, M. L., Frehlich, R. G., Eaton, F. D., Bishop, K. P., and Hugo, R. J.: In-situ turbulence measurement technique using state-of-the-art kite/blimp platforms, in: Proc. SPIE 3706, Airborne Laser Advanced Technology II, edited by: Steiner, T. D. and Merritt, P. H., 3706, 2-10, doi:10.1117/12.356947, 1999. 
Bange, J., Beyrich, F., and Engelbart, D. a. M.: Airborne measurements of turbulent fluxes during LITFASS-98: Comparison with ground measurements and remote sensing in a case study, Theor. Appl. Climatol., 73, 35-51, doi:10.1007/s00704002-0692-6, 2002.

Bange, J., Spieß, T., Herold, M., Beyrich, F., and Hennemuth, B.: Turbulent fluxes from Helipod flights above quasi-homogeneous patches within the LITFASS area, Bound.-Lay. Meteorol., 121, 127-151, doi:10.1007/s10546-006-9106-0, 2006.

BLLAST: BLLAST dataset, available at: http:/bllast.sedoo.fr/ database, last access: 7 January, 2016.

Braam, M., Beyrich, F., Bange, J., Platis, A., Martin, S., Maronga, B., and Moene, A. F.: On the Discrepancy in Simultaneous Observations of the Structure Parameter of Temperature Using Scintillometers and Unmanned Aircraft, Bound.-Lay. Meteorol., 158, 257-283, doi:10.1007/s10546-015-0086-9, 2016.

Båserud, L., Flügge, M., Bhandari, A., and Reuder, J.: Characterization of the SUMO Turbulence Measurement System for Wind Turbine Wake Assessment, Energy Procedia, 53, 173-183, doi:10.1016/j.egypro.2014.07.226, 2014.

Corsmeier, U.: Airborne turbulence measurements in the lower troposphere onboard the research aircraft Dornier 128-6, D-IBUF, Meteorol. Z., 10, 315-329, doi:10.1127/0941-2948/2001/00100315, 2001.

Darbieu, C., Lohou, F., Lothon, M., Vilà-Guerau de Arellano, J., Couvreux, F., Durand, P., Pino, D., Patton, E. G., Nilsson, E., Blay-Carreras, E., and Gioli, B.: Turbulence vertical structure of the boundary layer during the afternoon transition, Atmos. Chem. Phys., 15, 10071-10086, doi:10.5194/acp-1510071-2015, 2015.

Drüe, C. and Heinemann, G.: A Review and Practical Guide to In-Flight Calibration for Aircraft Turbulence Sensors, J. Atmos. Ocean. Tech., 30, 2820-2837, doi:10.1175/JTECH-D-1200103.1, 2013.

Elston, J., Argrow, B., Stachura, M., Weibel, D., Lawrence, D., and Pope, D.: Overview of Small Fixed-Wing Unmanned Aircraft for Meteorological Sampling, J. Atmos. Ocean. Tech., 32, 97-115, doi:10.1175/JTECH-D-13-00236.1, 2015.

ENAC: Paparazzi User's Manual, available at: http://wiki. paparazziuav.org/w/images/0/0a/Users_manual.pdf, 2008.

Frehlich, R.: Doppler lidar measurements of winds and turbulence in the boundary layer, IOP Conference Series: Earth and Environmental Science, 1, 012017, doi:10.1088/17551307/1/1/012017, 2008.

Gaynor, J. E.: Accuracy of sodar wind variance measurements, Int. J. Remote Sens., 15, 313-324, doi:10.1080/01431169408954075, 1994.

Guest, P. S.: Measuring turbulent heat fluxes over leads using kites, J. Geophys. Res., 112, C05021, doi:10.1029/2006JC003689, 2007.

Lampert, A., Pätzold, F., Jiménez, M. A., Lobitz, L., Martin, S., Lohmann, G., Canut, G., Legain, D., Bange, J., MartínezVillagrasa, D., and Cuxart, J.: A study of local turbulence and anisotropy during the afternoon and evening transition with an unmanned aerial system and mesoscale simulation, Atmos. Chem. Phys., 16, 8009-8021, doi:10.5194/acp-16-8009-2016, 2016.
Lenschow, D. H. (Ed.): Aircraft Measurements in the Boundary Layer, in: Probing the Atmospheric Boundary Layer, Am. Meteorol. Soc., Boston, MA, US, 39-55, 1986.

Lenschow, D. H. and Spyers-Duran, P.: Measurement Techniques: Air Motion Sensing, National Center for Atmospheric Research, Bulletin No. 23, available at: https://www.eol.ucar.edu/ raf/Bulletins/bulletin23.html, 1989.

Lenschow, D. H. and Stankov, B. B.: Length Scales in the Convective Boundary Layer, J. Atmos. Sci., 43, 1198-1209, doi:10.1175/1520-0469(1986)043<1198:LSITCB>2.0.CO;2, 1986.

Lothon, M., Couvreux, F., Donier, S., Guichard, F., Lacarrère, P., Lenschow, D. H., Noilhan, J., Saïd, F., Lacarrere, P., Lenschow, D. H., Noilhan, J., and Said, F.: Impact of coherent eddies on airborne measurements of vertical turbulent fluxes, Bound.Lay. Meteorol., 124, 425-447, doi:10.1007/s10546-007-9182-9, 2007.

Lothon, M., Lohou, F., Pino, D., Couvreux, F., Pardyjak, E. R., Reuder, J., Vilà-Guerau de Arellano, J., Durand, P., Hartogensis, O., Legain, D., Augustin, P., Gioli, B., Lenschow, D. H., Faloona I., Yagüe, C., Alexander, D. C., Angevine, W. M., Bargain, E., Barrié, J., Bazile, E., Bezombes, Y., Blay-Carreras, E., van de Boer, A., Boichard, J. L., Bourdon, A., Butet, A., Campistron, B., de Coster, O., Cuxart, J., Dabas, A., Darbieu, C., Deboudt, K., Delbarre, H., Derrien, S., Flament, P., Fourmentin, M., Garai, A., Gibert, F., Graf, A., Groebner, J., Guichard, F., Jiménez, M. A., Jonassen, M., van den Kroonenberg, A., Magliulo, V., Martin, S., Martinez, D., Mastrorillo, L., Moene, A. F., Molinos, F., Moulin, E., Pietersen, H. P., Piguet, B., Pique, E., RománCascón, C., Rufin-Soler, C., Saïd, F., Sastre-Marugán, M., Seity, Y., Steeneveld, G. J., Toscano, P., Traullé, O., Tzanos, D., Wacker, S., Wildmann, N., and Zaldei, A.: The BLLAST field experiment: Boundary-Layer Late Afternoon and Sunset Turbulence, Atmos. Chem. Phys., 14, 10931-10960, doi:10.5194/acp14-10931-2014, 2014.

Majumdar, A. K., Eaton, F. D., Jensen, M. L., Kyrazis, D. T., Schumm, B., Dierking, M. P., Shoemake, M. A., Dexheimer, D., and Ricklin, J. C.: Atmospheric turbulence measurements over desert site using ground-based instruments, kite/tetheredblimp platform, and aircraft relevant to optical communications and imaging systems: preliminary results, in: Proc. SPIE 6304, Free-Space Laser Communications VI, 63040X, doi:10.1117/12.684010, 2006.

Mansour, M., Kocer, G., Lenherr, C., Chokani, N., and Abhari, R. S.: Seven-Sensor Fast-Response Probe for Full-Scale Wind Turbine Flowfield Measurements, J. Eng. Gas Turb. Power, 133, 081601, doi:10.1115/1.4002781, 2011.

Martin, S., Bange, J., and Beyrich, F.: Meteorological profiling of the lower troposphere using the research UAV " $\mathrm{M}^{2} \mathrm{AV}$ Carolo", Atmos. Meas. Tech., 4, 705-716, doi:10.5194/amt-4-705-2011, 2011.

Muschinski, A., Frehich, R., Jensen, M., Hugo, R., Hoff, A., Eaton, F., and Balsley, B.: Fine-Scale Measurements Of Turbulence In The Lower Troposphere: An Intercomparison Between A Kite- And Balloon-Borne, And A Helicopter-Borne Measurement System, Bound.-Lay. Meteorol., 98, 219-250, doi:10.1023/A:1026520618624, 2001.

Pichugina, Y. L., Tucker, S. C., Banta, R. M., Brewer, W. A., Kelley, N. D., Jonkman, B. J., and Newsom, R. K.: Horizontal-Velocity 
and Variance Measurements in the Stable Boundary Layer Using Doppler Lidar: Sensitivity to Averaging Procedures, J. Atmos. Ocean. Tech., 25, 1307-1327, doi:10.1175/2008JTECHA988.1, 2008.

Reineman, B. D., Lenain, L., Statom, N. M., and Melville, W. K.: Development and Testing of Instrumentation for UAV-Based Flux Measurements within Terrestrial and Marine Atmospheric Boundary Layers, J. Atmos. Ocean. Tech., 30, 1295-1319, doi:10.1175/JTECH-D-12-00176.1, 2013.

Reuder, J., Brisset, P., Jonassen, M., Müller, M., and Mayer, S.: The Small Unmanned Meteorological Observer SUMO: A new tool for atmospheric boundary layer research, Meteorol. Z., 18, 141147, doi:10.1127/0941-2948/2009/0363, 2009.

Reuder, J., Jonassen, M., and Ólafsson, H.: The Small Unmanned Meteorological Observer SUMO: Recent developments and applications of a micro-UAS for atmospheric boundary layer research, Acta Geophys., 60, 1454-1473, doi:10.2478/s11600012-0042-8, 2012.

Reuder, J., Båserud, L., Jonassen, M. O., Kral, S. T., and Müller, M.: Exploring the potential of the RPA system SUMO for multipurpose boundary-layer missions during the BLLAST campaign, Atmos. Meas. Tech., 9, 2675-2688, doi:10.5194/amt-92675-2016, 2016.

Sathe, A. and Mann, J.: A review of turbulence measurements using ground-based wind lidars, Atmos. Meas. Tech., 6, 3147-3167, doi:10.5194/amt-6-3147-2013, 2013.

Sathe, A., Mann, J., Gottschall, J., and Courtney, M. S.: Can Wind Lidars Measure Turbulence?, J. Atmos. Ocean. Technol., 28, 853-868, doi:10.1175/JTECH-D-10-05004.1, 2011.

Seibert, P. and Langer, M.: Deriving characteristic parameters of the convective boundary layer from sodar measurements of the vertical velocity variance, Bound.-Lay. Meteorol., 81, 11-22, doi:10.1007/BF00119396, 1996.

Sjöholm, M., Mikkelsen, T., Mann, J., Enevoldsen, K., and Courtney, M.: Spatial averaging-effects on turbulence measured by a continuous-wave coherent lidar, Meteorol. Z., 18, 281-287, doi:10.1127/0941-2948/2009/0379, 2009.

Stevens, W. R., Squier, W., Mitchell, W., Gullett, B. K., and Pressley, C.: Measurement of motion corrected wind velocity using an aerostat lofted sonic anemometer, Atmos. Meas. Tech. Discuss., 6, 703-720, doi:10.5194/amtd-6-703-2013, 2013.
Stull, R.: An Introduction to Boundary Layer Meteorology, Springer, 670 pp., 1988.

Taylor, G. I.: The Spectrum of Turbulence, P. Roy. Soc. A-Math. Phy., 164, 476-490, doi:10.1098/rspa.1938.0032, 1938.

Thomas, P. and Vogt, S.: Intercomparison of turbulence data measured by SODAR and sonic anemometers, Bound.-Lay. Meteorol., 62, 353-359, doi:10.1007/BF00705564, 1993.

Thomas, R. M., Lehmann, K., Nguyen, H., Jackson, D. L., Wolfe, D., and Ramanathan, V.: Measurement of turbulent water vapor fluxes using a lightweight unmanned aerial vehicle system, Atmos. Meas. Tech., 5, 243-257, doi:10.5194/amt-5-243-2012, 2012.

van den Kroonenberg, A., Martin, T., Buschmann, M., Bange, J., and Vörsmann, P.: Measuring the Wind Vector Using the Autonomous Mini Aerial Vehicle $\mathrm{M}^{2} \mathrm{AV}$, J. Atmos. Ocean. Tech., 25, 1969-1982, doi:10.1175/2008JTECHA1114.1, 2008.

van den Kroonenberg, A. C., Martin, S., Beyrich, F., and Bange, J.: Spatially-Averaged Temperature Structure Parameter Over a Heterogeneous Surface Measured by an Unmanned Aerial Vehicle, Bound.-Lay. Meteorol., 142, 55-77, doi:10.1007/s10546011-9662-9, 2012.

Wildmann, N., Mauz, M., and Bange, J.: Two fast temperature sensors for probing of the atmospheric boundary layer using small remotely piloted aircraft (RPA), Atmos. Meas. Tech., 6, 21012113, doi:10.5194/amt-6-2101-2013, 2013.

Wildmann, N., Ravi, S., and Bange, J.: Towards higher accuracy and better frequency response with standard multi-hole probes in turbulence measurement with remotely piloted aircraft (RPA), Atmos. Meas. Tech., 7, 1027-1041, doi:10.5194/amt-7-1027-2014, 2014.

Wildmann, N., Rau, G. A., and Bange, J.: Observations of the Early Morning Boundary-Layer Transition with Small Remotely-Piloted Aircraft, Bound.-Lay. Meteorol., 157, 345373, doi:10.1007/s10546-015-0059-z, 2015. 